\title{
Albuminuria among Alaska Natives - Findings from the Genetics of Coronary Artery Disease in Alaska Natives (GOCADAN) Study
}

\author{
Stacey E. Jolly ${ }^{a}$ Carolyn J. Noonan $^{b}$ Yvette D. Roubideaux $^{d}$ \\ Jack H. Goldberg b, c Sven O.E. Ebbesson ${ }^{e}$ Jason G. Umans ${ }^{f, g}$ \\ Barbara V. Howard ${ }^{f, g}$ \\ a Medicine Department, Division of General Internal Medicine, University of California San Francisco, \\ San Francisco, Calif., b University of Washington Center for Clinical and Epidemiologic Research, and 'Seattle VA \\ Epidemiologic Research and Information Center, Seattle, Wash., 'Department of Family and Community Medicine, \\ College of Medicine, University of Arizona, Tucson, Ariz., eNorton Sound Health Corporation, Nome, Alaska, \\ ${ }^{\mathrm{f}}$ MedStar Research Institute, and ${ }^{9}$ Georgetown University Medical Center, Washington, D.C., USA
}

\section{Key Words}

Albuminuria $\cdot$ Kidney disease $\cdot$ Alaska Natives $\cdot$ Risk factor . Epidemiology

\begin{abstract}
Background: The prevalence and associated risk factors for albuminuria and low-grade albuminuria in Alaska Natives is not known. Methods: Cross-sectional analysis of the Genetics of Coronary Artery Disease in Alaska Natives Study. We included 1,026 individuals, who represent $85 \%$ of the study participants for whom complete data were available. Risk factors examined were age, sex, education, diabetes, hypertension, obesity, lipids, C-reactive protein, angiotensin-converting enzyme inhibitor use, and smoking status. Urine albumin excretion was estimated by the albumin/creatinine ratio measured from a single random morning urine sample. Albuminuria was defined as an albumin/creatinine ratio of $\geq 30 \mathrm{mg} / \mathrm{g}$. Low-grade albuminuria was defined as an albu$\mathrm{min} / \mathrm{creatinine}$ ratio of 10 to $<30 \mathrm{mg} / \mathrm{g}$. Results: The mean age was 42 years and over half were female. Diabetes prevalence was low at $3 \%$ and the prevalence of hypertension was
\end{abstract}

$20 \%$. The prevalence of albuminuria was $6 \%$; the prevalence of low-grade albuminuria was $12 \%$. Individuals with diabetes or hypertension were 3 times more likely to have albuminuria than those without these conditions [odd ratios: diabetes 3.0 (1.2-7.9) and hypertension 3.0 (1.2-7.3)]. Conclusions: The burden of albuminuria is low. Comprehensive programs and policies are important given the rise in diabetes and hypertension among Alaska Natives.

Copyright $\odot 2010$ S. Karger AG, Basel

\section{Introduction}

The prevalence of chronic kidney disease, a precursor to end-stage renal disease requiring dialysis, is increasing in the U.S. [1]. Albuminuria is a predictor of chronic kidney disease progression, end-stage renal disease, cardiovascular events, and mortality in the general population $[2,3]$. There is evidence that low-grade albuminuria, defined as less than $30 \mathrm{mg} / \mathrm{g}$, is also predictive of cardiovascular disease and death $[4,5]$.

\section{KARGER}

(c) 2010 S. Karger AG, Basel

Fax +41613061234 E-Mail karger@karger.ch www.karger.com www.karger.com/nec
Stacey Jolly, MD, MS

Cleveland Clinic Medicine Institute

9500 Euclid Avenue/G10

Cleveland, OH 44195 (USA)

Tel. +1 216444 8188, Fax +1 216445 1007, E-Mail jollys@ @cf.org 
American Indians and Alaska Natives (AIAN) have twice the incidence of end-stage renal disease compared to whites [6]. Among American Indians, studies find a $30-50 \%$ higher prevalence of albuminuria among individuals with diabetes [7-11] and also show a higher risk of cardiovascular disease and death among those with low-grade albuminuria [12]. Published data is not available on the prevalence of and the risk factors for albuminuria or low-grade albuminuria among Alaska Natives.

We use data from the Genetics of Coronary Artery Disease in Alaska Natives (GOCADAN) study to examine the prevalence of and the associated risk factors for albuminuria among Alaska Natives in the Norton Sound region on the Northwest coast of Alaska. This remote region of Alaska has a population that is predominantly Inupiat Eskimo. The purpose of our study is: (1) to estimate the age-specific prevalence of albuminuria among Alaska Native participants in GOCADAN; (2) to determine the independent association of sociodemographic and clinical risk factors with albuminuria, and (3) to estimate the prevalence and determine the associations of the risk factors with low-grade albuminuria.

\section{Methods}

\section{Study Design and Setting}

We conducted a cross-sectional secondary data analysis of the GOCADAN study. GOCADAN is an ongoing longitudinal, population-based study conducted to investigate the genetic and nongenetic determinants of cardiovascular disease and its risk factors in Alaska Natives. Details of the study design and methods are available elsewhere [13]. Briefly, a total of 1,214 predominantly Inupiat Eskimo participants were recruited from October 2000 through April 2004 in the Norton Sound region on the Northwest coast of Alaska. Participants completed an interviewer-administered survey of demographics and medical history, and underwent a complete physical examination, which included the collection of blood, urine, and anthropometric measurements.

Of the 1,214 GOCADAN participants in the study, we excluded participants for whom albuminuria status could not be obtained $(n=97)$ and who were younger than 18 years of age $(n=1)$. Out of the remaining 1,116 participants, we then excluded participants with missing data for our risk factors of interest $(\mathrm{n}=$ 90). Our final analytic sample constituted 1,026 participants in GOCADAN for whom complete data were available, which was $85 \%$ of the original sample. We compared the risk factors of interest among those included in our analysis $(n=1,026)$ versus those excluded $(n=90)$ using $\chi^{2}$ statistics and found a significant difference only for 2 risk factors. Those included were more likely to not have a high school education and have hypertension than those with missing data.

This study was approved by the research and ethics review board at Norton Sound Health Corporation and all relevant institutional review boards.

\section{Measures}

The primary outcome for our analysis was albuminuria. Urine albumin and creatinine were measured from a single morning sample. Urine albumin was assayed using an immunoturbidometric method (Diasorin SPQ reagents and calibrators, Stillwater, Minn., USA) on the Roche-Hitachi 717 platform (Basel, Switzerland) with the lowest assayed standard at $5.7 \mathrm{mg} / \mathrm{l}$ and a coefficient variation of $1.6 \%$ at $44 \mathrm{mg} / \mathrm{l}$. Urine creatinine was assayed using Vitros 250 CREA slides (Ortho Clinical Diagnostics, Raritan, N.J., USA) and a 2-point system, with a coefficient variation of $1.8 \%$ at $1.47 \mathrm{~g} / \mathrm{l}$. The urinary albumin (in $\mathrm{mg} / \mathrm{ml}$ ) to creatinine (in $\mathrm{g} / \mathrm{ml}$ ) ratio (ACR) was computed for those participants with a detectable, or greater than $5.7 \mathrm{mg} / \mathrm{l}$, urinary albumin level. An ACR $\geq 30 \mathrm{mg} / \mathrm{g}$ was the cutoff for a diagnosis of albuminuria. All those with an undetectable urinary albumin level were categorized as normal. The secondary outcome, low-grade albuminuria, was defined as an ACR in the range of 10 to $<30 \mathrm{mg} / \mathrm{g}$ and compared to normal, defined as an ACR $<10 \mathrm{mg} / \mathrm{g}$. Serum laboratory measurements of creatinine or cystatin $C$ are not available as they were not done as part of the baseline study.

The sociodemographic risk factors for this analysis included age, sex, and education. Age was calculated in years based on the verified date of birth during the GOCADAN interview and the examination date. Age was categorized as 18-34 years, 35-44 years, $45-54$ years, and $\geq 55$ years. Sex was defined as either female or male. Self-reported years of education were dichotomized as $<12$ years of school versus $\geq 12$ years of school or general equivalency diploma.

The clinical risk factors for this analysis included diabetes, hypertension, overweight/obesity, lipid levels, C-reactive protein (CRP), angiotensin-converting enzyme (ACE) inhibitor use, omega-3 fatty acid intake, and current smoking status. According to the American Diabetes Association 2003 diagnostic guidelines at the time of the study, diabetes was defined in GOCADAN as being present when participants reported previous or current use of either insulin or oral diabetes medication, had a recorded serum fasting glucose $\geq 126 \mathrm{mg} / \mathrm{dl}$ at the baseline exam, or had a recorded 2-hour glucose level $\geq 200 \mathrm{mg} / \mathrm{dl}$ after ingesting a 75 gram oral glucose load [14]. Impaired fasting glucose was defined as having a recorded fasting glucose of $100-125 \mathrm{mg} / \mathrm{dl}$ at the baseline exam or a recorded 2-hour glucose level of 140-199 mg/dl after ingesting a 75-gram oral glucose load [14].

Hypertensive status was categorized according to the Joint National Committee (JNC VII) guidelines in this analysis as hypertension, prehypertension, or normal [15]. Hypertension was defined as a systolic blood pressure $\geq 140 \mathrm{~mm} \mathrm{Hg}$ or a diastolic blood pressure $\geq 90 \mathrm{~mm} \mathrm{Hg}$, or reported use of anti-hypertensive medication by self-report. Prehypertension was defined as a systolic blood pressure $120-139 \mathrm{~mm} \mathrm{Hg}$ or a diastolic blood pressure 80-89 mm Hg. The body mass index (BMI) was calculated using measured weight (in pounds) and height (in inches) according to a standard formula and metric conversion $\left(\mathrm{BMI}=\right.$ weight $/$ height $^{2}$ $\left.\times 704.5 \mathrm{~kg} \mathrm{in}^{2} / \mathrm{lb} \mathrm{m}^{2}\right)$. We categorized BMI as normal $(\mathrm{BMI}<25)$, overweight (BMI 25-29), and obese (BMI $\geq 30$ ).

Lipids were obtained from a fasting blood sample and were measured by an auto analyzer [13]. All lipid measurements were dichotomized at clinically meaningful cutoff points: total cholesterol $\geq 200 \mathrm{mg} / \mathrm{dl}$; high-density lipoprotein (HDL) $<40 \mathrm{mg} / \mathrm{dl}$; low-density lipoprotein $\geq 130 \mathrm{mg} / \mathrm{dl}$, and triglycerides $\geq 150 \mathrm{mg} /$ dl [16]. High-sensitivity CRP was obtained from serum analysis 
of the GOCADAN participants. CRP was dichotomized using the clinically meaningful cutoff of $\geq 3 \mathrm{mg} / \mathrm{dl}$ [17]. ACE inhibitor use was defined as either self-report of ACE inhibitor medication use or ACE inhibitor use that was ascertained during the medication inventory from the baseline exam. Omega-3 fatty acid intake was ascertained from the dietary survey portion of the exam. We created a combined measure of eicosapentaenoic acid and docosahexaenoic acid in grams that was analyzed as a continuous variable [18]. Smoking status was obtained by self-report during the structured interview portion of the examination and was categorized as never, former, or current smoker.

\section{Statistical Analysis}

Descriptive statistics for participant characteristics were calculated using means and standard deviations for continuous variables and percents for categorical variables. We computed the overall prevalence of albuminuria in our sample of GOCADAN participants. We reported the prevalence of low-grade albuminuria $(10$ to $<30 \mathrm{mg} / \mathrm{g})$. We then calculated the prevalence of albuminuria and corresponding 95\% confidence intervals (CI) separately by age categories. We ran the analyses using a method to account for a study with large and inter-related families (data not shown). Our results did not change and so we present here the ordinary logistic regression models.

To assess the association between albuminuria and the selected risk factors, we fit logistic regression models. Initially, we fit a series of univariate regression models to estimate the association of each potential risk factor with albuminuria, unadjusted for other risk factors. We fit a series of multivariate models that adjusted for risk factors by category (e.g. demographics, clinical measures, health behaviors) to affirm the robustness of a single multivariate model given the low number of outcomes in our study. We then fit a single multivariate model that simultaneously adjusted for all relevant risk factors. From this multivariate adjusted model, we estimated the independent association of each risk factor with albuminuria and derived adjusted odds ratios (OR) and 95\% CI.

Potential risk factors were determined a priori and included in regressions regardless of significance in either univariate or multivariate models, except for omega-3 fatty acid intake. In the sensitivity analysis, omega-3 fatty acid intake was not significant in our models and so was excluded in order to maximize our power/ sample size due to missing values. Age was examined as both a continuous and categorical variable; results were similar and we present categorical age in the final analysis. We examined the interaction of hypertension and diabetes by including their product term in the multivariate model.

We also examined the association of low-grade albuminuria with selected risk factors. Those with albuminuria (defined as $\geq 30 \mathrm{mg} / \mathrm{g}$ ) were excluded from this analysis. Using the same a priori risk factors, we fit a series of univariate logistic regression models, followed by a single multivariate model that simultaneously adjusted for all the risk factors comparing low-grade albuminuria $(10$ to $<30 \mathrm{mg} / \mathrm{g})$ to normal $(<10 \mathrm{mg} / \mathrm{g})$.

We used a complete case analysis approach in which we analyzed GOCADAN participants for whom complete data were available for all variables of interest. STATA version 10.0 (StataCorp LP 2008, College Station, Tex., USA) was used for all data manipulation and analysis.

Albuminuria among Alaska Natives

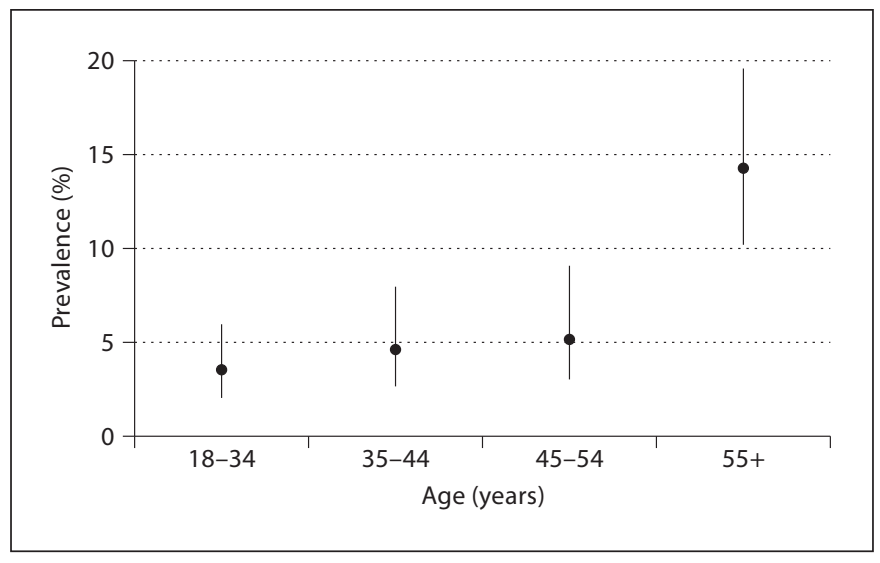

Fig. 1. Prevalence and 95\% CI for albuminuria by age categories among participants of the GOCADAN study $(n=1,026)$.

\section{Results}

The mean age of our sample was 42 years (standard deviation 16 years; range 18-91 years). The prevalence of albuminuria was $6 \%(n=64)$. The prevalence of albuminuria increased with age from $3 \%$ among participants 18 34 years to $14 \%$ in participants $\geq 55$ years (fig. 1 ). Of those with albuminuria, $9 \%(n=6)$ had macroalbuminuria, or an ACR $>300 \mathrm{mg} / \mathrm{g}$.

Participants with albuminuria were more likely to be older, female, and have less than a high school education compared to participants without albuminuria (table 1). The prevalence of diabetes was higher among participants with albuminuria compared to those without (20 vs. $2 \%)$. Hypertension was more common among participants with albuminuria as well (50 vs. $18 \%$ ). There was some overlap between diabetes and hypertension. Among the 34 participants with diabetes, the majority (80\%) also had hypertension. Conversely, among the 207 participants with hypertension only $13 \%$ also had diabetes. Participants with albuminuria had a higher prevalence of obesity, HDL $<40 \mathrm{mg} / \mathrm{dl}$, triglycerides $\geq 150 \mathrm{mg} / \mathrm{dl}$, CRP $\geq 3 \mathrm{mg} / \mathrm{dl}$, and ACE inhibitor use. Smoking status was similar among participants with and without albuminuria.

In unadjusted and adjusted analyses, diabetes and hypertension were most strongly associated with albuminuria (table 2). Even after adjustment for all risk factors, the odds of albuminuria were approximately 3 times higher in participants with either diabetes $(\mathrm{OR}=3.0,95 \%$ $\mathrm{CI}=1.2-7.9)$ or hypertension $(\mathrm{OR}=3.0,95 \% \mathrm{CI}=1.2-7.3)$ compared to participants without the condition. The in- 
Table 1. Characteristics of participants of the GOCADAN study by albuminuria status $(n=1,026)$

\begin{tabular}{|c|c|c|}
\hline & $\begin{array}{l}\text { Albuminuria } \\
\text { absent } \\
(\mathrm{n}=962)\end{array}$ & $\begin{array}{l}\text { Albuminuria } \\
\text { present } \\
(\mathrm{n}=64)\end{array}$ \\
\hline Sociodemographics & $\mathrm{n}(\%)$ & $\mathrm{n}(\%)$ \\
\hline \multicolumn{3}{|l|}{ Age, years } \\
\hline $18-34$ & $341(35)$ & $12(19)$ \\
\hline $35-44$ & $236(25)$ & $11(17)$ \\
\hline $45-54$ & $203(21)$ & $11(17)$ \\
\hline$\geq 55$ & $182(19)$ & $30(47)$ \\
\hline \multicolumn{3}{|l|}{ Sex } \\
\hline Females & $543(56)$ & $45(70)$ \\
\hline Males & $419(44)$ & $19(30)$ \\
\hline \multicolumn{3}{|l|}{ Education, years } \\
\hline Less than high school, $<12$ years & $194(20)$ & $28(44)$ \\
\hline High school or greater, $\geq 12$ years & $768(80)$ & $36(56)$ \\
\hline Clinical measures & $\mathrm{n}(\%)$ & $\mathrm{n}(\%)$ \\
\hline \multicolumn{3}{|l|}{ Glycemic status } \\
\hline Normal glucose status & $804(84)$ & $43(67)$ \\
\hline Impaired fasting glucose & $137(14)$ & $8(13)$ \\
\hline Diabetes & $21(2)$ & $13(20)$ \\
\hline \multicolumn{3}{|l|}{ Hypertension, JNC 7 definition } \\
\hline Normal & $456(47)$ & $14(22)$ \\
\hline Prehypertension & $331(34)$ & $18(28)$ \\
\hline Hypertension & $175(18)$ & $32(50)$ \\
\hline \multicolumn{3}{|l|}{ BMI } \\
\hline Normal, BMI $<25$ & $379(39)$ & $18(28)$ \\
\hline Overweight, BMI 25-29 & $306(32)$ & $17(27)$ \\
\hline Obesity, BMI $\geq 30$ & $277(29)$ & $29(45)$ \\
\hline \multicolumn{3}{|l|}{ Total cholesterol, mg/dl } \\
\hline$<200$ & $493(51)$ & $34(53)$ \\
\hline$\geq 200$ & $469(49)$ & $30(47)$ \\
\hline \multicolumn{3}{|l|}{ High-density lipoprotein, mg/dl } \\
\hline$<40$ & $98(10)$ & $12(19)$ \\
\hline$\geq 40$ & $864(90)$ & $52(81)$ \\
\hline \multicolumn{3}{|l|}{ Low-density lipoprotein, mg/dl } \\
\hline$<130$ & $644(67)$ & $51(80)$ \\
\hline$\geq 130$ & $318(33)$ & $13(20)$ \\
\hline \multicolumn{3}{|l|}{ Triglycerides, mg/dl } \\
\hline$<150$ & $721(75)$ & $43(67)$ \\
\hline$\geq 150$ & $241(25)$ & $21(33)$ \\
\hline \multicolumn{3}{|l|}{ High-sensitivity CRP, mg/dl } \\
\hline$<3$ & $763(79)$ & $44(69)$ \\
\hline$\geq 3$ & $199(21)$ & $20(31)$ \\
\hline \multicolumn{3}{|l|}{ ACE inhibitor } \\
\hline No & $918(95)$ & $51(80)$ \\
\hline Yes & $44(5)$ & $13(20)$ \\
\hline \multicolumn{3}{|c|}{ Mean omega- 3 fatty acid intake $\pm S D$} \\
\hline \multicolumn{3}{|l|}{ Smoking status } \\
\hline Never & $180(19)$ & $15(23)$ \\
\hline Former smoker & $200(21)$ & $14(22)$ \\
\hline Current smoker & $582(60)$ & $35(55)$ \\
\hline
\end{tabular}

Data are frequency (\%) except for omega-3 fatty acid intake which has an $\mathrm{n}=945$ due to missing values. JNC $7=$ Joint National Committee 7 guidelines.
Table 2. Unadjusted and adjusted $O R$ for albuminuria among participants in the GOCADAN study $(n=1,026)$

\begin{tabular}{|c|c|c|}
\hline & $\begin{array}{l}\text { Unadjusted } \\
\text { OR (95\% CI) }\end{array}$ & $\begin{array}{l}\text { Adjusted }^{1} \\
\text { OR }(95 \% \mathrm{CI})\end{array}$ \\
\hline \multicolumn{3}{|l|}{ Sociodemographics } \\
\hline \multicolumn{3}{|l|}{ Age, years } \\
\hline $18-34$ & referent & referent \\
\hline $35-44$ & $1.3(0.6-3.1)$ & $1.6(0.7-4.0)$ \\
\hline $45-54$ & $1.5(0.7-3.6)$ & $1.7(0.7-4.3)$ \\
\hline$\geq 55$ & $4.7(2.3-9.4)$ & $2.7(1.0-7.0)$ \\
\hline \multicolumn{3}{|l|}{ Sex } \\
\hline Males & referent & referent \\
\hline Females & $1.8(1.1-3.2)$ & $2.1(1.1-3.9)$ \\
\hline \multicolumn{3}{|l|}{ Education, years } \\
\hline \multicolumn{3}{|l|}{ Less than high school } \\
\hline \multicolumn{3}{|l|}{ High school or greater } \\
\hline$\geq 12$ years & $0.3(0.2-0.6)$ & $0.6(0.3-1.1)$ \\
\hline \multicolumn{3}{|l|}{ Clinical measures } \\
\hline \multicolumn{3}{|l|}{ Glycemic status } \\
\hline Normal glucose status & referent & referent \\
\hline Impaired fasting glucose & $1.1(0.5-2.4)$ & $0.6(0.2-1.4)$ \\
\hline Diabetes & $11.6(5.4-24.7)$ & $3.0(1.2-7.9)$ \\
\hline \multicolumn{3}{|c|}{ Hypertension, JNC 7 definition } \\
\hline Normal & referent & referent \\
\hline Prehypertension & $1.8(0.9-3.6)$ & $2.0(0.9-4.2)$ \\
\hline Hypertension & $6.0(3.1-11.4)$ & $3.0(1.2-7.3)$ \\
\hline \multicolumn{3}{|l|}{ BMI } \\
\hline Normal, BMI $<25$ & referent & referent \\
\hline Overweight, BMI 25-29 & $1.2(0.6-2.3)$ & $1.0(0.5-2.0)$ \\
\hline Obesity, BMI $\geq 30$ & $2.2(1.2-4.1)$ & $1.5(0.7-3.1)$ \\
\hline \multicolumn{3}{|l|}{ Total cholesterol, mg/dl } \\
\hline$<200$ & referent & referent \\
\hline$\geq 200$ & $0.9(0.6-1.5)$ & $1.2(0.6-2.4)$ \\
\hline \multicolumn{3}{|c|}{ High-density lipoprotein, mg/dl } \\
\hline$<40$ & referent & referent \\
\hline$\geq 40$ & $0.5(0.3-1.0)$ & $0.4(0.2-0.8)$ \\
\hline \multicolumn{3}{|l|}{ Low-density lipoprotein, mg/dl } \\
\hline$<130$ & referent & referent \\
\hline$\geq 130$ & $0.5(0.3-1.0)$ & $0.5(0.2-1.0)$ \\
\hline \multicolumn{3}{|l|}{ Triglycerides, mg/dl } \\
\hline$<150$ & referent & referent \\
\hline$\geq 150$ & $1.5(0.9-2.5)$ & $0.7(0.4-1.4)$ \\
\hline \multicolumn{3}{|l|}{ High-sensitivity CRP, mg/dl } \\
\hline$<3$ & referent & referent \\
\hline$\geq 3$ & $1.7(1.0-3.0)$ & $1.1(0.6-2.1)$ \\
\hline \multicolumn{3}{|l|}{ ACE inhibitor } \\
\hline No & referent & referent \\
\hline Yes & $5.3(2.7-10.5)$ & $1.5(0.6-3.7)$ \\
\hline \multicolumn{3}{|l|}{ Smoking status } \\
\hline Never & referent & referent \\
\hline Former smoker & $0.8(0.4-1.8)$ & $0.8(0.3-1.9)$ \\
\hline Current smoker & $0.7(0.4-1.4)$ & $1.3(0.6-2.8)$ \\
\hline
\end{tabular}

${ }^{1}$ Simultaneously adjusted for all risk factors. JNC $7=$ Joint National Committee 7 guidelines. 
Table 3. Unadjusted and adjusted OR for low-grade albuminuria (10 to $<30 \mathrm{mg} / \mathrm{g}$ ) among participants in the GOCADAN study $(\mathrm{n}=962)$

Unadjusted Adjusted ${ }^{1}$ OR (95\% CI) OR (95\% CI)

\begin{tabular}{lll}
$\begin{array}{l}\text { Sociodemographics } \\
\text { Age, years }\end{array}$ & & \\
$18-34$ & & \\
$35-44$ & referent & referent \\
$45-54$ & $1.1(0.6-1.9)$ & $1.0(0.5-1.8)$ \\
$\geq 55$ & $1.4(0.8-2.4)$ & $1.0(0.5-1.9)$ \\
Sex & $3.7(2.3-6.2)$ & $1.8(0.9-3.6)$ \\
$\quad$ Males & & \\
$\quad$ Females & referent & referent \\
Education, years & $1.9(1.2-2.8)$ & $2.2(1.3-3.4)$ \\
$\quad$ Less than high school, $<12$ years & referent & referent \\
High school or greater, $\geq 12$ years & $0.4(0.2-0.6)$ & $0.5(0.3-0.9)$ \\
\hline
\end{tabular}

Clinical measures

Glycemic status

Normal glucose status Impaired fasting glucose Diabetes

Hypertension, JNC 7 definition Normal Prehypertension BMI Hypertension

Normal, BMI <25

Overweight, BMI 25-29

Obesity, BMI $\geq 30$

Total cholesterol, mg/dl $<200$ $\geq 200$

High-density lipoprotein, mg/dl $<40$ $\geq 40$

Low-density lipoprotein, mg/dl $<130$ $\geq 130$

Triglycerides, mg/dl $<150$ $\geq 150$

High-sensitivity CRP, mg/dl $<3$ $\geq 3$

ACE inhibitor

No Yes

Smoking status Never Former smoker Current smoker

${ }^{1}$ Simultaneously adjusted for all risk factors. JNC $7=$ Joint National Committee 7 guidelines. $\begin{array}{ll}\text { referent } & \text { referent } \\ 3.3(2.1-5.1) & 2.6(1.6-4.5) \\ 2.9(1.0-8.0) & 1.3(0.4-4.4) \\ & \\ \text { referent } & \text { referent } \\ 1.2(0.8-1.9) & 1.2(0.7-2.0) \\ 2.6(1.6-4.2) & 2.0(1.0-3.7)\end{array}$

referent referent $0.9(0.6-1.5) \quad 0.8(0.5-1.3)$ $1.5(1.0-2.4) \quad 1.0(0.6-1.7)$

referent referent $1.2(0.8-1.7) \quad 0.9(0.5-1.6)$

referent referent $1.5(0.7-3.0) \quad 1.5(0.7-3.3)$

referent referent $1.2(0.8-1.8) \quad 1.2(0.7-2.2)$

referent referent $0.9(0.6-1.5) \quad 0.8(0.5-1.3)$

referent referent $2.2(1.5-3.4) \quad 2.0(1.2-3.1)$

referent referent $1.5(0.7-3.5) \quad 0.6(0.2-1.5)$

referent referent $0.9(0.5-1.6) \quad 0.7(0.4-1.3)$ $0.6(0.4-1.0) \quad 0.7(0.4-1.1)$ teraction of diabetes and hypertension was not significant $(\mathrm{p}=0.48)$ and was not included in the final model. Table 2 also shows that older age $(\mathrm{OR}=2.7,95 \% \mathrm{CI}=$ $1.0-7.0)$ and female sex $(\mathrm{OR}=2.1,95 \% \mathrm{CI}=1.1-3.9)$ were independent risk factors for albuminuria. Elevated HDL was associated with lower odds of albuminuria.

Table 3 presents the unadjusted and adjusted OR and 95\% CI comparing the odds of low-grade albuminuria for selected risk factors among the 962 participants without albuminuria. Of those participants, $12 \%(\mathrm{n}=120)$ had an ACR in the range of 10 to $<30 \mathrm{mg} / \mathrm{g}$, i.e. low-grade albuminuria. Those with low-grade albuminuria, compared to those with normal or undetectable albuminuria, were more likely to be female, not have completed high school, and have impaired fasting glucose, diabetes, hypertension, and elevated CRP levels. In the multivariate regression model, only female sex, not having a high school degree, impaired fasting glucose, and elevated CRP levels remained significant.

\section{Discussion}

This was the first study to examine the prevalence and risk factors for albuminuria and low-grade albuminuria among Alaska Natives. The prevalence of albuminuria among Alaska Native participants in GOCADAN was low compared to several empirical studies of AIAN populations in the lower 48 states $[9,10,19]$. Even when compared to the $10 \%$ prevalence in the general US population [1], the $6 \%$ prevalence we found in Alaska Natives is striking in comparison. Diabetes and hypertension were both found to be important risk factors for albuminuria as seen in other populations.

Given the low prevalence of diabetes in our study participants, it is not surprising that the prevalence of albuminuria was also low. Among some AIAN populations in the lower 48 states, diabetes prevalence is nearly $70 \%$ [10], whereas in our study of GOCADAN participants, the prevalence of diabetes was just 3\%. Hypertension was more common among our GOCADAN participants, and it is an important independent risk factor for albuminuria $[20,21]$. Our prevalence of hypertension was slightly less than that found among US adults [22] and among some AIAN in the lower 48 states [10]. However, our prevalence of hypertension was nearly double the prevalence that was found among a different population of Alaska Natives [23]. Compared to those without albuminuria, we found that those with albuminuria were more likely to be either treated with or receiving an ACE 
inhibitor. This may reflect confounding by indication, given the use of these drugs to control albuminuria or hypertension, especially among patients with diabetes [24]. In contrast to other studies [25], a high HDL was found to be associated with a lower risk for albuminuria in our sample, which included those with and without diabetes.

Impaired fasting glucose and prehypertension are precursors to diabetes and hypertension, respectively, and they were found to be common among this group. A prior study among American Indians found an association with impaired fasting glucose and albuminuria [26]. We found that impaired fasting glucose was independently associated with low-grade albuminuria. These factors may be a harbinger of problems to come in the future for this population that traditionally had low risk factors for cardiovascular and kidney disease. In the Strong Heart Study, a longitudinal cardiovascular study conducted among American Indians, the prevalence of hypertension at baseline was $28 \%$ in both men and women; over 4 years, it rose to $36 \%$ among men and women [27]. Obesity, an important risk factor for impaired fasting glucose, diabetes, and hypertension, is increasing among Alaska Natives [28-30]. The results of this study indicate the need for prevention efforts before the prevalence of albuminuria and its risk factors increase in this population.

In addition, we found that the risk was higher of having low-grade albuminuria levels among those with elevated CRP, consistent with albuminuria as a marker of vascular dysfunction [31]. Low-grade albuminuria was also associated with hypertension. These findings relate to the ongoing discussion in the literature about where to draw the cut-point for the definition of microalbuminuria [32].

While there are important strengths of the GOCADAN study, such as having carefully defined clinical measures determined by laboratory analysis and standardized blood pressure measurements [13], our study has several limitations. Our data are cross-sectional and therefore we cannot account for changes in the risk factors or albuminuria status over time. As in most epidemiologic studies, a single random sample of urine was used to measure albumin and creatinine, rather than repeated measures as recommended for clinical practice [33]. This may have lead to misclassification or overestimation of the outcome albuminuria. We did not have complete data on all GOCADAN participants, nor did we have serum creatinine or cystatin $\mathrm{C}$ data available for which to estimate kidney function. However, we found that those with missing risk factor data were generally similar to those who had complete data, except for a small excess in hypertension among those with missing data. The modest number of albuminuria cases in our study makes it challenging to fit a multivariate model that simultaneously adjusts for all risk factors and confounders. However, the multivariate adjusted analysis, that included both diabetes and hypertension, did reduce the size of the OR compared to the unadjusted estimates. Our findings are derived from a specific geographic region in Alaska, and though representative of the people in that region, our results may not be generalizable to all Alaska Natives.

In summary, we found a low burden of albuminuria among this Alaska Native population. The low prevalence of albuminuria in this population provides an opportunity for continued education, prevention, and research. While risk factors for albuminuria such as hypertension, diabetes, and obesity are not as prevalent as in other populations, public health reports indicate that they are increasing [34-36]. Understanding the risk factors and prevalence of albuminuria and chronic kidney disease will be important in helping to develop interventions to keep the burden of disease low in this population.

\section{Acknowledgements}

The authors are grateful to the Norton Sound Health Corporation, GOCADAN staff, and all the study participants of GOCADAN. This paper was supported by the National Institute on Aging grant P30AG031057-01 and the National Heart, Lung and Blood Institute grants RO1-HL64244, U01HL082458, and M10RR0047-34 from the National Institutes of Health, Bethesda, Md., USA.

References

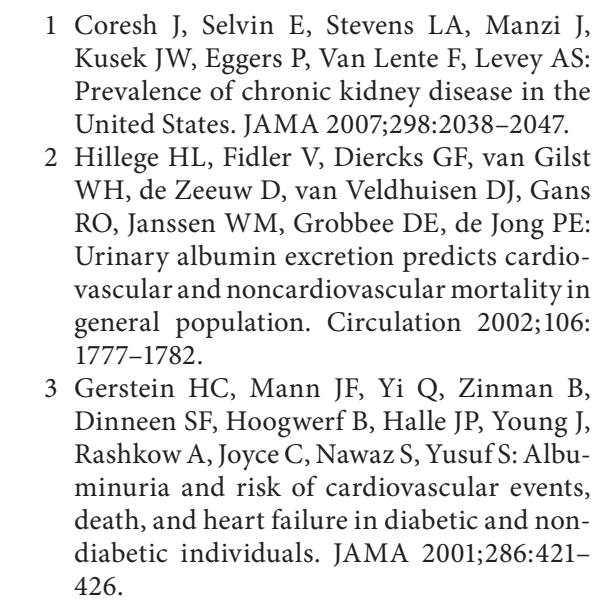

Jolly/Noonan/Roubideaux/Goldberg/ Ebbesson/Umans/Howard 
4 Arnlov J, Evans JC, Meigs JB, Wang TJ, Fox CS, Levy D, Benjamin EJ, D'Agostino RB, Vasan RS: Low-grade albuminuria and incidence of cardiovascular disease events in nonhypertensive and nondiabetic individuals: the Framingham Heart Study. Circulation 2005;112:969-975.

5 Klausen K, Borch-Johnsen K, Feldt-Rasmussen B, Jensen G, Clausen P, Scharling H, Appleyard M, Jensen JS: Very low levels of microalbuminuria are associated with increased risk of coronary heart disease and death independently of renal function, hypertension, and diabetes. Circulation 2004; 110:32-35.

6 United States Renal Data System: USRDS 2006 Annual Data Report. Bethesda, National Institute of Diabetes and Digestive and Kidney Diseases, National Institutes of Health, 2006.

$\checkmark 7$ Hirata-Dulas CA, Rith-Najarian SJ, McIntyre MC, Ross C, Dahl DC, Keane WF, Kasiske BL: Risk factors for nephropathy and cardiovascular disease in diabetic northern Minnesota American Indians. Clin Nephrol 1996;46:92-98.

-8 Kasiske BL, Rith-Najarian S, Casper ML, Croft JB: American Indian heritage and risk factors for renal injury. Kidney Int 1998;54: 1305-1310.

-9 Nelson RG, Morgenstern H, Bennett PH: An epidemic of proteinuria in Pima Indians with type 2 diabetes mellitus. Kidney Int 1998;54:2081-2088.

10 Robbins DC, Knowler WC, Lee ET, Yeh J, Go OT, Welty T, Fabsitz R, Howard BV: Regional differences in albuminuria among American Indians: an epidemic of renal disease. Kidney Int 1996;49:557-563.

-11 Sosenko JM, Hu D, Welty T, Howard BV, Lee E, Robbins DC: Albuminuria in recent-onset type 2 diabetes: the Strong Heart Study. Diabetes Care 2002;25:1078-1084.

-12 Xu J, Knowler WC, Devereux RB, Yeh J, Umans JG, Begum M, Fabsitz RR, Lee ET: Albuminuria within the 'normal' range and risk of cardiovascular disease and death in American Indians: the Strong Heart Study. Am J Kidney Dis 2007;49:208-216.

$\checkmark 13$ Howard BV, Devereux RB, Cole SA, Davidson M, Dyke B, Ebbesson SO, Epstein SE, Robinson DR, Jarvis B, Kaufman DJ, Laston S, MacCluer JW, Okin PM, Roman MJ, Romenesko T, Ruotolo G, Swenson M, Wenger CR, Williams-Blangero S, Zhu J, Saccheus C, Fabsitz RR, Robbins DC: A genetic and epidemiologic study of cardiovascular disease in Alaska Natives (GOCADAN): design and methods. Int J Circumpolar Health 2005;64:206-221.

14 Genuth S, Alberti KG, Bennett P, Buse J, Defronzo R, Kahn R, Kitzmiller J, Knowler WC, Lebovitz H, Lernmark A, Nathan D, Palmer J, Rizza R, Saudek C, Shaw J, Steffes M, Stern M, Tuomilehto J, Zimmet P: Follow-up report on the diagnosis of diabetes mellitus. Diabetes Care 2003;26:3160-3167.
15 Chobanian AV, Bakris GL, Black HR, Cushman WC, Green LA, Izzo JL Jr, Jones DW, Materson BJ, Oparil S, Wright JT Jr, Roccella EJ: The seventh report of the Joint National Committee on prevention, detection, evaluation, and treatment of high blood pressure: the JNC 7 Report. JAMA 2003;289:25602572.

16 Third report of the National Cholesterol Education Program (NCEP) expert panel on detection, evaluation, and treatment of high blood cholesterol in adults (Adult Treatment Panel III). Final report. Circulation 2002; 106:3143-3421.

-17 Pearson TA, Mensah GA, Alexander RW, Anderson JL, Cannon RO 3rd, Criqui M, Fadl YY, Fortmann SP, Hong Y, Myers GL, Rifai N, Smith SC Jr, Taubert K, Tracy RP, Vinicor F: Markers of inflammation and cardiovascular disease: application to clinical and public health practice: a statement for healthcare professionals from the Centers for Disease Control and prevention and the American Heart Association. Circulation 2003;107:499-511.

- 18 Ebbesson SO, Roman MJ, Devereux RB, Kaufman D, Fabsitz RR, Maccluer JW, Dyke B, Laston S, Wenger CR, Comuzzie AG, Romenesko T, Ebbesson LO, Nobmann ED, Howard BV: Consumption of omega-3 fatty acids is not associated with a reduction in carotid atherosclerosis: the Genetics of Coronary Artery Disease in Alaska Natives study. Atherosclerosis 2008;199:346-353.

19 Shah VO, Scavini M, Stidley CA, Tentori F, Welty TK, MacCluer JW, Narva AS, Bobelu A, Albert CP, Kessler DS, Harford AM, Wong CS, Harris AA, Paine S, Zager PG: Epidemic of diabetic and nondiabetic renal disease among the Zuni Indians: the Zuni Kidney Project. J Am Soc Nephrol 2003;14:13201329.

$\checkmark 20 \mathrm{~K} / \mathrm{DOQI}$ clinical practice guidelines for chronic kidney disease: evaluation, classification, and stratification. Am J Kidney Dis 2002;39:S1-S266.

21 Brown WW, Peters RM, Ohmit SE, Keane WF, Collins A, Chen SC, King K, Klag MJ, Molony DA, Flack JM: Early detection of kidney disease in community settings: the Kidney Early Evaluation Program (KEEP). Am J Kidney Dis 2003;42:22-35.

22 Racial/ethnic disparities in prevalence, treatment, and control of hypertension United States, 1999-2002. MMWR 2005;54: 7-9.

23 Murphy NJ, Schraer CD, Theile MC, Boyko EJ, Bulkow LR, Doty BJ, Lanier AP: Hypertension in Alaska Natives: association with overweight, glucose intolerance, diet and mechanized activity. Ethn Health 1997;2: 267-275
24 Sarafidis PA, Khosla N, Bakris GL: Antihypertensive therapy in the presence of proteinuria. Am J Kidney Dis 2007;49:12-26.

25 Xu J, Lee ET, Devereux RB, Umans JG, Bella JN, Shara NM, Yeh J, Fabsitz RR, Howard BV: A longitudinal study of risk factors for incident albuminuria in diabetic American Indians: the Strong Heart Study. Am J Kidney Dis 2008;51:415-424.

-26 Hoehner CM, Greenlund KJ, Rith-Najarian S, Casper ML, McClellan WM: Association of the insulin resistance syndrome and microalbuminuria among nondiabetic Native Americans. The Inter-Tribal Heart Project. J Am Soc Nephrol 2002;13:1626-1634.

27 Welty TK, Rhoades DA, Yeh F, Lee ET, Cowan LD, Fabsitz RR, Robbins DC, Devereux RB, Henderson JA, Howard BV: Changes in cardiovascular disease risk factors among American Indians. The Strong Heart Study. Ann Epidemiol 2002;12:97106.

28 Hiratsuka VY, Loo R, Will JC, Oberrecht R, Poindexter P: Cardiovascular disease risk factor screening among Alaska Native women: the traditions of the heart project. Int J Circumpolar Health 2007;66(suppl 1):3944.

29 Mohatt GV, Plaetke R, Klejka J, Luick B, Lardon C, Bersamin A, Hopkins S, Dondanville M, Herron J, Boyer B: The Center for Alaska Native Health Research Study: a community-based participatory research study of obesity and chronic disease-related protective and risk factors. Int J Circumpolar Health 2007;66:8-18

-30 Murphy NJ, Schraer CD, Thiele MC, Boyko EJ, Bulkow LR, Doty BJ, Lanier AP: Dietary change and obesity associated with glucose intolerance in Alaska Natives. J Am Diet Assoc 1995;95:676-682.

-31 Deckert T, Feldt-Rasmussen B, Borch-Johnsen K, Jensen T, Kofoed-Enevoldsen A: Albuminuria reflects widespread vascular damage: the steno hypothesis. Diabetologia 1989;32:219-226.

>32 Knight EL, Curhan GC: Albuminuria: moving beyond traditional microalbuminuria cut-points. Curr Opin Nephrol Hypertens 2003; $12: 283-284$

33 National Kidney Foundation: Kidney Disease Outcomes Quality Initiative Guideline. Am J Kidney Dis 2002;39:S32-S36.

34 Diagnosed diabetes among American Indians and Alaska Natives aged $<35$ years United States, 1994-2004. MMWR 2006;55: 1201-1203.

-35 Diabetes prevalence among American Indians and Alaska Natives and the overall population - United States, 1994-2002. MMWR 2003;52:702-704.

-36 Boyer BB, Mohatt GV, Plaetke R, Herron J, Stanhope KL, Stephensen C, Havel PJ: Metabolic syndrome in Yup'ik Eskimos: the Center for Alaska Native Health Research (CANHR) Study. Obesity 2007;15:25352540 . 